\title{
WEAR ANALYSIS BY TAGUCHI TECHNIQUE OF Al6061 BASED HYBRID COMPOSITE REINFORCED WITH SiC AND Al2O3
}

\author{
APARMIT SHIVAM ${ }^{1}$, AMIT SINGLA ${ }^{2} \&$ AMIT CHAUHAN ${ }^{3}$ \\ ${ }^{I}$ Research Scholar, Department of Mechanical Engineering, Chandigarh University, Punjab, India \\ ${ }^{2}$ Indian Institute of Packaging, Mumbai, Maharashtra, India \\ ${ }^{3}$ Assistant Professor, Department of Mechanical Engineering, Punjab University, Punjab, India
}

\begin{abstract}
In this paper, wear characteristics of hybrid composite of Al6061 was studied. Hybrid composite was reinforced with silicon carbide $(\mathrm{SiC})$ with varying $(3 \%, 6 \%, 9 \%)$ weight \% and keeping the alumina (Al2O3) with constant (10) weight percentage. Stir casting method was used to fabricate the composite. T6 heat treatment was applied on the sample before doing the wear test. Pin on disc apparatus was used to perform the wear test. SEM was performed to do the microstructural analysis. It was found that hardness and density of samples increased as the percentage of SiC increases. 19 orthogonal array was applied to check the interaction between different wear parameters using the Taguchi technique.

KEYWORDS: AMC, SiC, Al2O3 \& S/N Ratio
\end{abstract}

Received: Jul 07, 2017; Accepted: Jul 27, 2017; Published: Aug 05, 2017; Paper Id.: IJMPERDAUG201737

\section{INTRODUCTION}

MMC (metal matrix composite) is one of the topics on which so much work has been done in last decade. This is due to its advantages over conventional monolithic material system. In modern engineering application we need materials which improve the efficiency of our system and reduce the losses. [1, 2]The benefit of metal matrix composite is that we can tailor its properties as per our need. In metal matrix composite, continuous phase said to be as matrix and non-continuous, dispersed phase is reinforcement which can be in the form of particle, flake or fibre. Because of these reinforcement MMCs possess superior properties than the matrix material. Usually the matrix materials used in MMCs are light metal such as $\mathrm{Al}, \mathrm{Mg}$ and Ti etc. [3, 4] However AMCs (aluminium matrix composite) are the most utilized ones this is due to its properties such as excellent wear resistance, satisfactory corrosion resistance, good thermal conductivity and high strength to weight ratio. [5, 6, 7]AMCs have wide range of application in automobile industries, sport industries and in commercial usage. Another benefit of $\mathrm{AMC}$ over other MMC is cost; it is less expensive than other MMCs available. Reinforcement which is key factor of deciding the property of MMC does not preferred in continuous form in AMCs because discontinuously distributed ceramic particle have merits over continuously reinforced aluminium. [8, 9, 10] But discontinuously distributed conventional reinforcements have some constraints too which are its cost and its availability. [12]In some of the researches it was found that DRAMC has poor fracture toughness and ductility. [9, 12] To overcome this problem researchers have tried various ways one of those is reducing the size of the reinforced particle to Nano size but again it increases the cost of the composite. In developing countries industrial and agriculture waste such as rice husk, red mud etc. used as reinforcement with synthetic reinforcement and result shown that it 
increases the property of composite significantly than the base alloy used.[13, 14, 15]

Particle reinforced composites have shown excellent tribological properties and wear of composite is an important part of the study, but it is least focussed topic of tribology. When two surfaces are in relative motion to each other wear happens and it results into micro cracks and material loss. Wear of machine parts led to lower efficiency, power loss, and frequent part replacement. [16, 17, 18, 19, 20]By changing the mechanical parameters such as applied load, temperature, counter face hardness, sliding distance etc. and material factors wear properties of material changes. By adding solid lubricants as reinforcement into composite, the wear properties increase significantly. [21] In many research studies it was found that oxide formation on the contact surface of material reduces wear. On the other hand at higher temperature smoothly burnished layer formation occurs with a glaze. [22]A Researcher conducted an experimental study on Aluminium based metal matrix composite reinforced with A12O3, it was fabricated by squeeze casting methodology result has shown that coarser particle has shown more homogenous distribution as compared to fine particles of reinforcement. It was found that finer particles of reinforcement led to segregation and porosity due to thermal mismatch of matrix material and reinforcement. AMCs can be fabricated by various processing techniques such as solid state processing as well as liquid state processing. [21]

\section{MATERIALS}

Base material and reinforcement are the deciding factors for the properties of any composite. We can tailor the properties of composite by varying the material.

\section{Matrix Material in Stir Casting Method}

Aluminium 6061 is used as matrix material to prepare the hybrid composite. Aluminium 6061 is a heat treatable alloy of 6000 series which is used in various industrial applications. Al 6061 has good mechanical properties which makes it preferable choice as matrix material in aluminium composite. Table 2.1 shows the chemical composition of Al 6061 and Table 2.2 shows the physical and mechanical properties of aluminium 6061.

Table 1: Chemical Composition of Al6061 (wt. \%) [23]

\begin{tabular}{|c|l|l|l|l|l|l|l|l|l|l|}
\hline $\begin{array}{c}\text { 0.15- } \\
\mathbf{0 . 4 0}\end{array}$ & $\begin{array}{c}\mathbf{0 . 1 5} \\
\text { Max. }\end{array}$ & $\mathbf{0 . 8 - 1 . 2}$ & $\begin{array}{c}\mathbf{0 . 7} \\
\text { Max. }\end{array}$ & $\mathbf{0 . 4 - 0 . 8}$ & $\begin{array}{c}\mathbf{0 . 2 5} \\
\text { Max. }\end{array}$ & $\begin{array}{c}\mathbf{0 . 0 4}- \\
\mathbf{0 . 3 5}\end{array}$ & $\mathbf{0 . 0 6}$ & $\begin{array}{c}\mathbf{0 . 1 5} \\
\text { Max. }\end{array}$ & $\begin{array}{c}\text { 0.15 } \\
\text { Total, } \\
\text { 0.05 Max } \\
\text { Each }\end{array}$ & Balance \\
\hline $\mathrm{Cu}$ & $\mathrm{Mn}$ & $\mathrm{Mg}$ & $\mathrm{Fe}$ & $\mathrm{Si}$ & $\mathrm{Zn}$ & $\mathrm{Cr}$ & $\mathrm{Ni}$ & $\mathrm{Ti}$ & others & $\mathrm{Al}$ \\
\hline
\end{tabular}

Table 2: Mechanical and Physical Properties of Al6061 [25]

\begin{tabular}{|c|c|c|c|}
\hline Density (g/cc) & $\begin{array}{c}\text { Modulus of } \\
\text { Elasticity }(\mathbf{G P a})\end{array}$ & $\begin{array}{c}\text { Coefficient of Thermal } \\
\text { Expansion }\left(\mathbf{m} / \mathbf{m}-{ }^{\circ} \mathbf{C}\right)\end{array}$ & Fracture Toughness $(\mathbf{M P a} \sqrt{ } \mathbf{m})$ \\
\hline 2.72 & 70 & $25 \times 10^{-6}$ & 29.1 \\
\hline
\end{tabular}

\section{Reinforcements in Stir Casting Method}

Silicon carbide $(\mathrm{SiC})$ and Alumina $(\mathrm{Al} 2 \mathrm{O} 3)$ have been used as reinforcement with base material. Mesh size of Sic and $\mathrm{Al} 2 \mathrm{o} 3$ is $80-100$ and 70-230 micron respectively. In various research works it was found that $\mathrm{SiC}$ improves the hardness of composite and A12O3 improves tribological properties of aluminium composites. 


\section{METHODOLOGY}

\section{Fabrication Process}

In this work Alumina and $\mathrm{SiC}$ reinforced hybrid composite is prepared by stir casting technique. Al6061 was first heated above its melting temperature and then gradually its temperature decreased up to its semi solid state. Beside this reinforcements $\mathrm{SiC}\left(3,6\right.$ and $9 \mathrm{wt} \%$ ) and Alumina (10 wt\% fixed) were preheated to $400^{\circ} \mathrm{c}$ and maintained at this temperature for 20 minutes. Preheating was done to avoid foreign particle and moisture. Preheating also promotes proper mixing. Mechanical stirrer was used to create the vortex in crucible before introducing Magnesium (1 wt\%, fixed) and reinforcements. To increase the wettability of reinforcements with melted Al6061, magnesium was introduced. To obtain the homogenous mixture of reinforcements with matrix material mechanical stirring was continued for 6 minutes. After the stirring process mild steel die was used to cast the composite. After the 30 minutes composite was taken out.

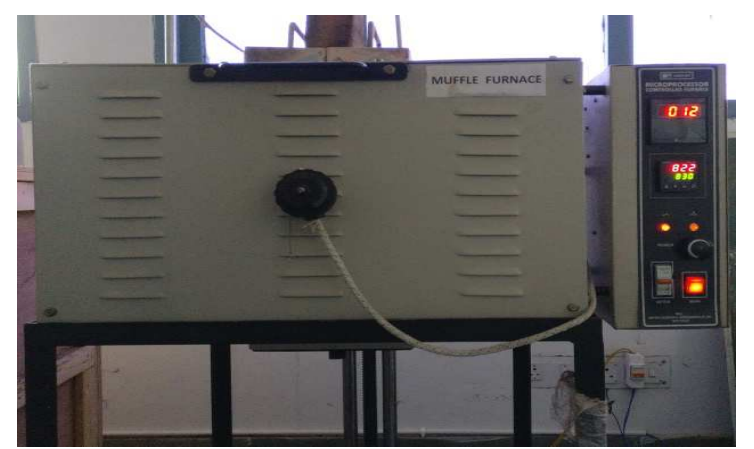

Figure 1: Muffle Furnace used to melt the Al6061 Alloy

\section{Sample Preparation}

The casted composite of three different compositions was machined on lathe machine into cylindrical shape. Dimension of the sample were kept 30mm height and $10 \mathrm{~mm}$ diameter.

\section{Hardness}

Hardness test was performed on Rockwell hardness machine. As aluminium is a soft material so the hardness test was performed on B scale. Load applied on the indentation ball was $60 \mathrm{~kg}$-f. Pin was indented at various places on different sample and mean value was taken.

\section{Density}

The purpose of determining the density of the composite is to know the effect of reinforcement wt $\%$ on the density of the composite. Archimedes principal was used to calculate the density of the composite. To calculate the density we first calculate the mass of samples in air and then in water by using a setup. Formula was used to calculate the density is

$$
\rho=\frac{m_{a}}{m_{a}-m_{w}}
$$

Where, $m_{a}$ is mass of sample in air and $m_{w}$ is mass of sample in water and $\rho$ denotes density of the sample.

\section{Wear Test}

Wear test was performed on pin on disc wear machine which helps to study the wear and friction characteristics of 
the specimen. Tribological properties of specimen were tested under dry sliding condition at room temperature. Pin was held stationary perpendicular to the rotating disc. Computer monitor was facilitated to record the tangential force and wear with the help of electronic sensors. Emery paper of grit size 220, 320, 400, 600, 800 and 1000 were rubbed against the contacting surface of the pin to lessen the surface roughness. Acetone was used to clean the specimen before the test was performed. Wear loss is calculated through electronic balance machine of high precision (0.0001 gm). Schematic diagram of pin on disc machine is given in figure 2.

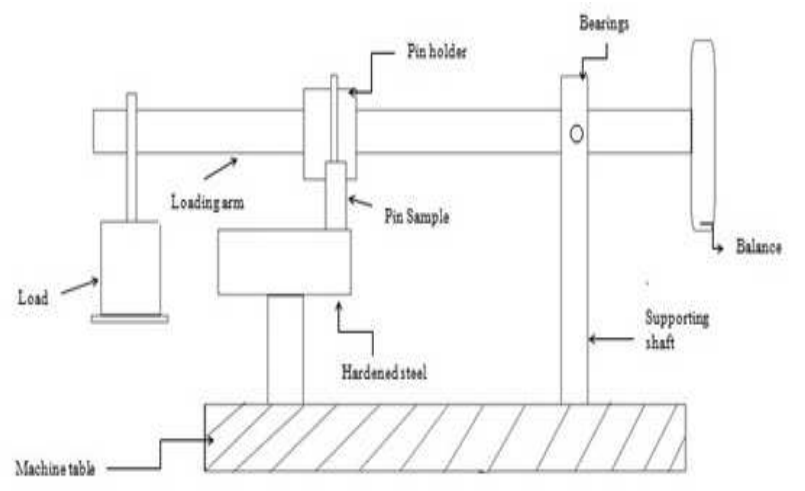

Figure 2: Schematic Diagram of Pin on Disc Wear Machine

Sliding speed at which test was performed are taken as 0.4, 0.8 and $1.2 \mathrm{in} \mathrm{m/s}$ and sliding distance are varied as 2000, 4000 and 6000 in meter. Loads are taken as 1.5, 3 and 4.5 in kg-f. To design the experiment and analyse the result Taguchi technique is applied. By applying the Taguchi technique we can enhance the quality of the result. We applied L9 orthogonal array to find the optimum result and to observe that which parameter is affecting the properties of composite the most.

\section{Experimental Design}

If we attempt to perform complete design of experiments (DOE) it will take so much time and money by adopting factorial design, we reduce the time. But as per design point of view it might not be the best option. Taguchi technique helps us to adopt orthogonal array and it is accurate and increase the quality of experimental results. In this research workL9 orthogonal array is used with a total of four factors of three levels each. Design summary and DOE as L9 orthogonal array is shown in Table 3 and 4 respectively.

Table 3: Design Summary

\begin{tabular}{|l|c|}
\hline Taguchi Array & $\mathbf{L 9}\left(\mathbf{3}^{\wedge} \mathbf{4}\right)$ \\
\hline Factors: & 4 \\
\hline Runs: & 9 \\
\hline
\end{tabular}

Table 4: DOE as L9 Orthogonal Array

\begin{tabular}{|c|c|c|c|c|c|}
\hline $\begin{array}{c}\text { Exp } \\
\text { No }\end{array}$ & $\begin{array}{c}\text { \% } \\
\text { Value } \\
\text { of SiC }\end{array}$ & Load(kg-f) & $\begin{array}{c}\text { Sliding } \\
\text { Distance(m) }\end{array}$ & Speed(m/s) & $\begin{array}{c}\text { Weight } \\
\text { Loss(gm) }\end{array}$ \\
\hline 1 & 3 & 1.5 & 2000 & 0.4 & 0.0093 \\
\hline 2 & 3 & 3 & 4000 & 0.8 & 0.0414 \\
\hline 3 & 3 & 4.5 & 6000 & 1.2 & 0.1012 \\
\hline 4 & 6 & 1.5 & 4000 & 1.2 & 0.008 \\
\hline 5 & 6 & 3 & 6000 & 0.4 & 0.0242 \\
\hline
\end{tabular}




\begin{tabular}{|l|l|c|c|c|c|}
\hline 6 & 6 & 4.5 & 2000 & 0.8 & 0.0264 \\
\hline 7 & 9 & 1.5 & 6000 & 0.8 & 0.0268 \\
\hline 8 & 9 & 3 & 2000 & 1.2 & 0.0265 \\
\hline 9 & 9 & 4.5 & 6000 & 0.4 & 0.0253 \\
\hline
\end{tabular}

\section{RESULTS AND DISCUSSIONS}

\section{Density}

Graph is plotted between density of specimen and the percentage variation of $\mathrm{SiC}$ in different composite sample. In graph we can see that as the percentage of SiC increases the density of composite is gradually increasing. This is due to increase in presence of $\mathrm{SiC}$ in the composite as its density is more than the matrix material.

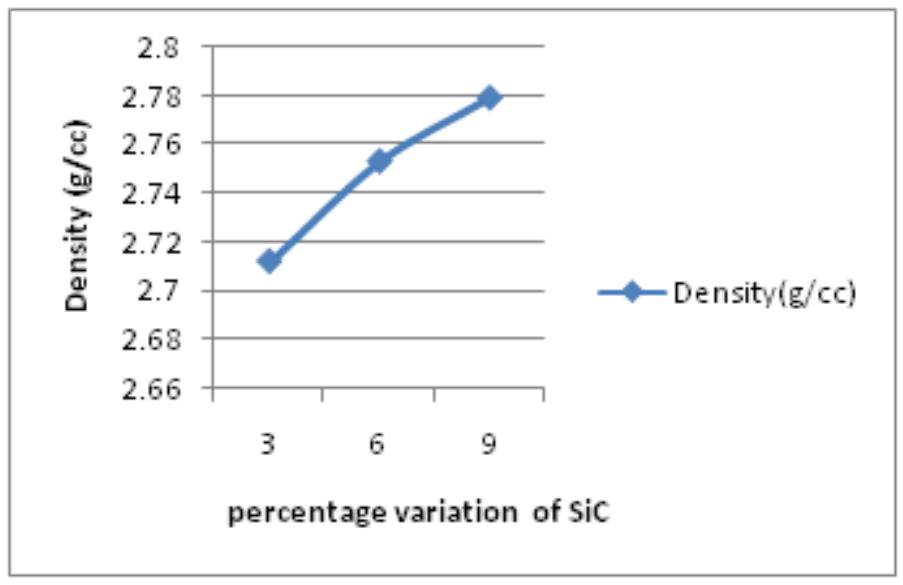

Figure 3: Density Variation Curve

\section{Microstructure Analysis}

Microstructure of composite and interface between reinforcement and matrix play the vital role deciding the mechanical and tribological properties of composite [21]. SEM (scanning electron microscope) images were taken of Al6061 alloy hybrid composite reinforced with Alumina and SiC. In figure 4 (a), we can observe the clustering of alumina particles. As this is a machined surface of composite sample and also due to air entrapment while introducing reinforcement during casting we see some porosities. Non homogenous mixture of reinforcement is found in figure 4 (a) and this is due to contact time variation during fabrication process of composite. In figure 4(b) reinforcement particles are found all over the surface but porosities are quite more than the figure 4(a).
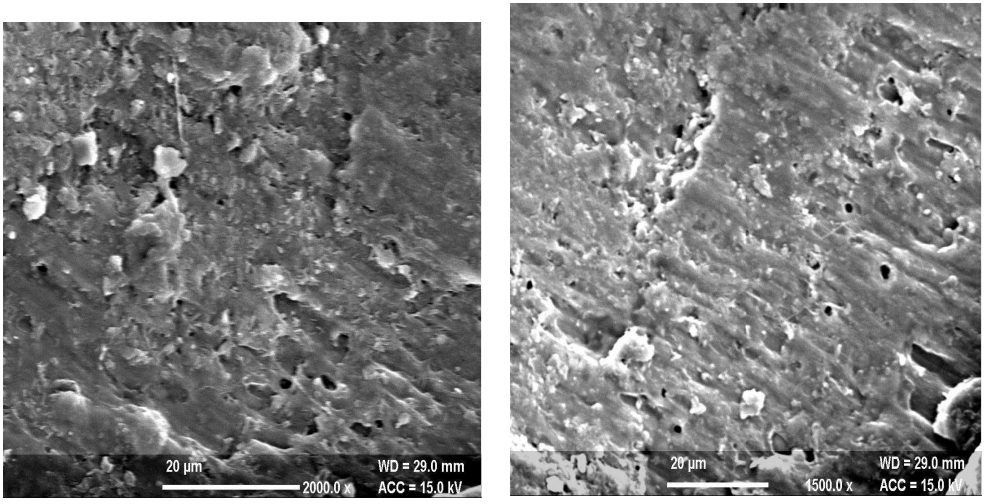

Figure 4 (a) Figure 4(b): SEM Images of Hybrid Composite 


\section{Hardness}

Reinforcements share the load and indentation with matrix material which we apply on composite. We can see in graph as we increase the wt\% percentage of $\mathrm{SiC}$ in composite. Its hardness increases gradually. As we know $\mathrm{SiC}$ is a hard particle and it creates pinning effect which is the reason for increased hardness of composite.

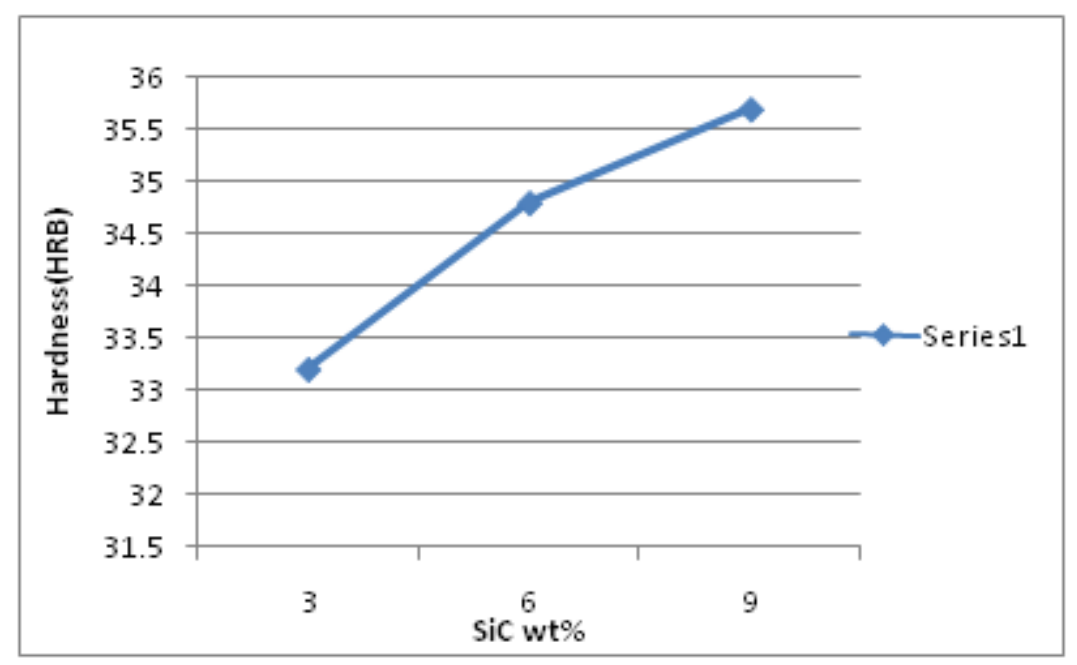

Figure 5: Hardness Graph with Respect to $\mathrm{SiC}$ wt\%

\section{Wear Analysis}

In Table 5, by applying Taguchi technique test results are converted into $\mathrm{S} / \mathrm{N}$ ratio. $\mathrm{S} / \mathrm{N}$ ratio shows that how much quality of result digressing from the desired value. $\mathrm{S} / \mathrm{N}$ ratio is of three classes i.e. nominal the better, smaller the better and larger the better. In this study smaller the better is selected because we want weight loss to minimum. Equation to calculate $\mathrm{S} / \mathrm{N}$ ratio is as follows: [24]

$\mathrm{N}=-10 \log _{10}[$ meanofsumofsquareofmeasureddata $]$

Table 5: L9 OA with Columns of Weight Loss and S/N Ratio

\begin{tabular}{|c|c|c|c|c|c|}
\hline \% Value of SiC & Load(kg-f) & Sliding Distance & Speed & Weight Loss(gm) & SNRA1 \\
\hline 3 & 1.5 & 2000 & 0.4 & 0.0093 & 40.63034 \\
\hline 3 & 3 & 4000 & 0.8 & 0.0414 & 27.65999 \\
\hline 3 & 4.5 & 6000 & 1.2 & 0.1012 & 19.89639 \\
\hline 6 & 1.5 & 4000 & 1.2 & 0.008 & 41.9382 \\
\hline 6 & 3 & 6000 & 0.4 & 0.0242 & 32.32369 \\
\hline 6 & 4.5 & 2000 & 0.8 & 0.0264 & 31.56792 \\
\hline 9 & 1.5 & 6000 & 0.8 & 0.0268 & 31.4373 \\
\hline 9 & 3 & 2000 & 1.2 & 0.0265 & 31.53508 \\
\hline 9 & 4.5 & 4000 & 0.4 & 0.0253 & 31.93759 \\
\hline
\end{tabular}

Figure 6 and 7 show the effect of control factor on weight loss. By averaing the values of response for each factor level main efect plot for data means is plotted. The slope of graph lines is useful to determine relative magnitude of effect of factors. Figure 8 shows the interaction between different factors fow weight loss. By interactin plots we can observe that how much one factor is affecting another one. 


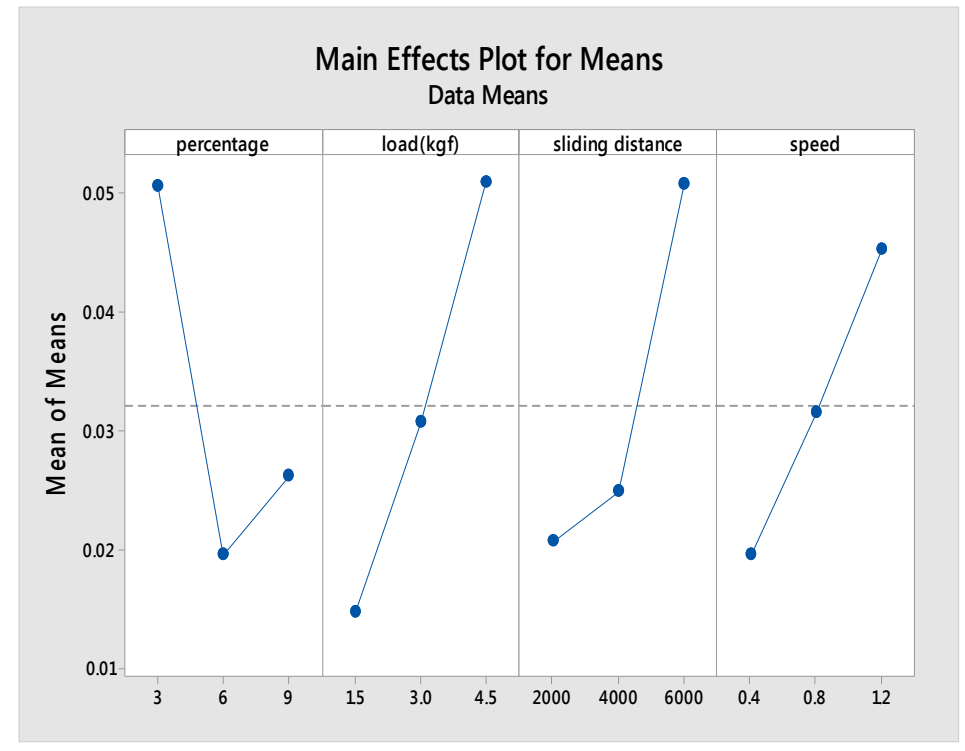

Figure 6: Main Effect Plot for Means

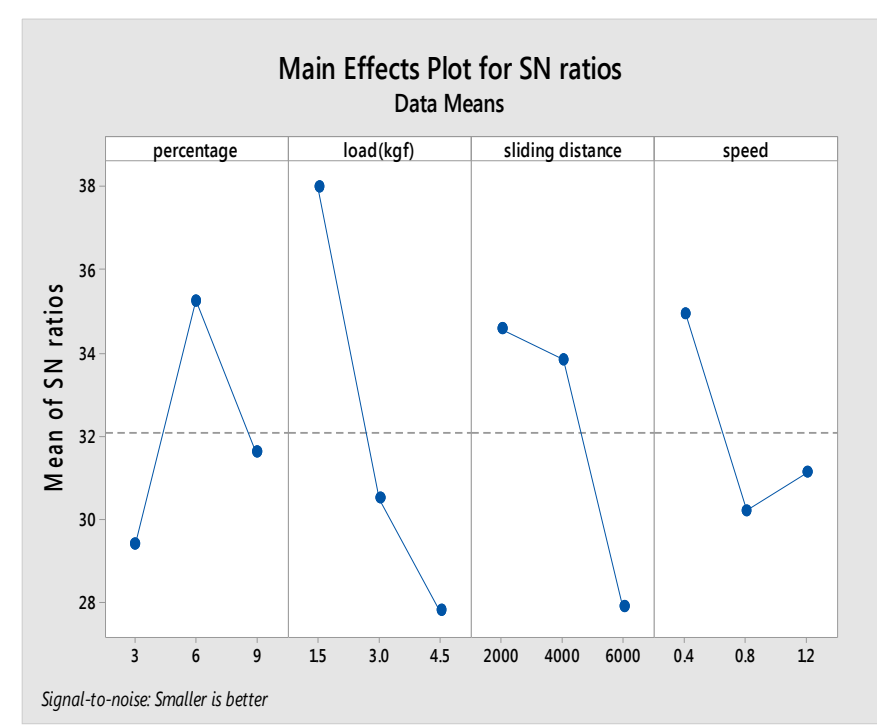

Figure 7: Main Effect Plot for S/N Ratio

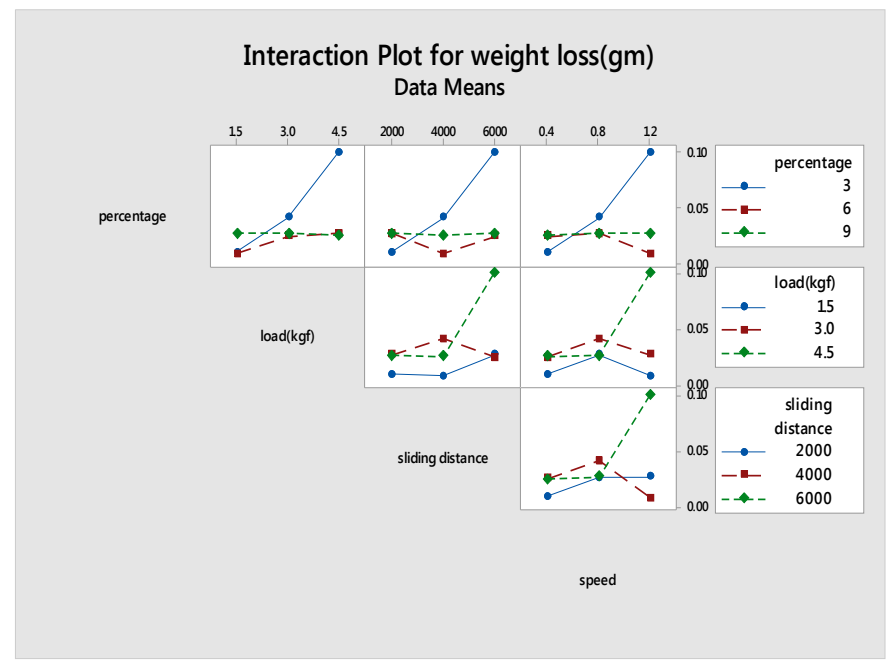

Figure 8: Interaction Plot for Weight Loss 
Table 6 represents the response for means and ranking has been provided for each factor. The similar table is provided for signal to noise ratio. In response table for signal to noise ratio we can see that load is the factor which is ranked one and it implies load applied to the sample is affecting most the weight loss. And after load sliding distance, weight percentage of silicon carbide and speed are affecting the weight loss in the descending order.

Table 6: Response Table for Means (Smaller is better)

\begin{tabular}{|c|c|c|c|c|}
\hline Level & Percentage & Load(kg-f) & Sliding Distance & Speed \\
\hline 1 & 0.05063 & 0.0147 & 0.02073 & 0.0196 \\
\hline 2 & 0.01953 & 0.0307 & 0.0249 & 0.03153 \\
\hline 3 & 0.0262 & 0.05097 & 0.05073 & 0.04523 \\
\hline Delta & 0.0311 & 0.03627 & 0.03 & 0.02563 \\
\hline Rank & 2 & 1 & 3 & 4 \\
\hline
\end{tabular}

Table 7: Response Table for Signal to Noise Ratios (Smaller is better)

\begin{tabular}{|c|c|c|c|c|}
\hline Level & Percentage & load(kg-f) & Sliding & Speed \\
\hline & & & distance & \\
\hline 1 & 29.4 & 38 & 34.58 & 34.96 \\
\hline 2 & 35.28 & 30.51 & 33.85 & 30.22 \\
\hline 3 & 31.64 & 27.8 & 27.89 & 31.12 \\
\hline Delta & 5.88 & 10.2 & 6.69 & 4.74 \\
\hline Rank & 3 & 1 & 2 & 4 \\
\hline
\end{tabular}

\section{CONCLUSIONS}

In this experimental work we studied the wear properties of hybrid composite reinforced with alumina powder with fixed wt.\% (10\%) and silicon carbide with varying wt.\% (3\%, 6\%, 9\%) using Taguchi technique. We also calculated the density and hardness of hybrid composite and did the micro structural study. From that following conclusions are withdrawn.

- We find out that the density of hybrid composite increases as we increase the wt. $\%$ of silicon carbide.

- We can conclude that, SiC plays the important role in increasing the hardness of the composite. As find out in graph (Figure 4) hardness gradually increases by increasing the wt\% of $\mathrm{SiC}$.

- Taguchi technique successfully used to determine the triblogical properties of AMC with the help of MINITAB 18. In predefined factors with three levels each in DOE load is the factor which is affecting the weight loss the most and in the response Table for $\mathrm{S} / \mathrm{N}$ ratio we can see it.

- The main effect plot for means shows that the weight loss increases with the increase in speed, sliding distance and load. With the increase in the content of $\mathrm{SiC}$, weight loss first decreases and then increases.

\section{REFERENCES}

1. Tjong SC. Processing and deformation characteristics of metals reinforced with ceramic nanoparticles. In: Tjong S-C, editor. Nano crystalline materials [Internet], 2nd ed. Oxford: Elsevier; 2014. p. 269-304 [cited 2014 Aug 25].

2. Rino JJ, Chandramohan D, Sucitharan KS, Jebin VD. Anoverview on development of aluminium metal matrix composites with hybrid reinforcement, IJSR India Online, ISSN 2012:2319-7064.

3. Casati R, Vedani M, Metal matrix composites reinforced bynano-particles—a review. Metals 2014;4(1):65-83.

4. Alaneme KK, Olubambi PA. Corrosion and wear behaviour of rice husk ash-alumina reinforced Al-Mg-Si alloy matrix hybrid 
composites. J Mater Res Technol 2013; 2(2):188-94.

5. Das DK, Mishra PC, Singh S, Pattanaik S. Fabrication and heat treatment of ceramic-reinforced aluminium matrix composites - a review. Int J Mech Mater Eng 2014; 9(1):1-15.

6. Alaneme KK, Bodunrin MO. Mechanical behaviour of alumina reinforced AA 6063 metal matrix composites developed by two steps - stir casting process. Acta Tech Corvininesis - Bull Eng 2013;6(3) [cited 2014 Aug 25],[Internet] available from:http://acta. fih. upt. ro/pdf/2013-3/ACTA-2013-3-18.pdf

7. Alaneme KK, Aluko AO. Fracture toughness (K1C) and tensile properties of as-cast and age-hardened aluminium (6063) silicon carbide particulate composites. Sci Iran2012; 19(4):992-6.

8. Surappa MK. Aluminium matrix composites: challenges and opportunities. Sadhana 2003; 28(1-2):319-34.

9. Kok M. Production and mechanical properties of Al2O3particle-reinforced 2024 aluminium alloy composites. JMater Process Technol 2005; 161(3):381-7.

10. SirahbizuYigezu B, Mahapatra MM, Jha PK. Influence of reinforcement type on microstructure, hardness, and tensile properties of an aluminium alloy metal matrix composite. JMiner Mater Charact Eng 2013; 1(4):124-30.

11. Oghenevweta JE, Aigbodion VS, Nyior GB, Asuke F. Mechanical properties and micro structural analysis ofAl-SiMg/carbonized maize stalk waste particulate composites. J King Saud Univ - Eng Sci [Internet] 2014 [cited2014 Aug 25], available from: http://www.sciencedirect.com/science/article/pii/S1018363914000245

12. Bhandakkar A, Prasad RC, Sastry SM. Fracture toughness ofAA2024 aluminium fly ash metal matrix composites. Int JCompos Mater 2014; 4(2):108-24.

13. Loh YR, Sujan D, Rahman ME, Das CA. Sugarcane bagasse-the future composite material: a literature review. Resour Conserv Recycl 2013; 75:14-22.

14. Anilkumar HC, Hebbar HS, Ravishankar KS. Mechanical properties of fly ash reinforced aluminium alloy (Al6061) composites. Int J Mech Mater Eng 2011;6(1):41-5.

15. Aigbodion VS, Hassan SB, DAUDA ET. The development of mathematical model for the prediction of ageing behaviour for Al$\mathrm{Cu}-\mathrm{Mg} /$ Bagasse Ash Particulate Composites experimental study of ageing behaviour of Al-Cu-Mg/bagasse ash particulate composites, Trib Ind 2010;9(10):28.

16. G.B.V. Kumar, C.S.P. Rao, N. Selvaraj, M.S. Bhagyashekar. "Studies on Al6061-SiC and Al7075-Al 2 O 3 Metal Matrix Composites", Journal of Minerals \& Materials Characterization and Engineering, Vol. 9, pp.43-55, 2010

17. S.K. Ghosh, P. Saha. "Crack and wear behavior of SiC particulate reinforced aluminium based metal matrix composite fabricated by direct metal laser sintering process", Materials \& Design, vol. 32, pp.139-145, 2011.

18. K.C. Ludema, 'ASM Handbook: Friction, Lubrication and Wear Technology', ASM International, vol. 18, pp.236-241, 1998.

19. U. Sánchez-Santana, C. Rubio-González, G. Gomez-Rosas, J.L. Ocana, C. Molpeceres, J. Porro, M. Morales, "Wear and friction of 6061-T6 aluminum alloy treated by laser shock processing", Wear, vol. 260, pp.847-54, 2006.

A. Martín, J. Rodriguez, J. Llorca. "Temperature effects on the wear behavior of particulate reinforced Al-based composites", Wear, vol. 225-229, pp.615-20, 1999.

20. Jaswinder Singh, Amit Chauhan (2016), "Overview of wear performance of aluminium matrix composites reinforced with ceramic materials under the influence of controllable variables”, Ceramics International42 (2016) pp.56-81.

21. Pragya Shandilya, P. K. Jain, Neelesh Kumar Jain (2010), “Study on average cutting speed in WEDM of SiCp/6061 Al MMC 
based on RSM", Conference: Proc. of 4th International Conference on Advances in Mechanical Engineering (ICAME 2010), 23-25 September, At SVNIT, Surat, India, Volume: $4^{\text {th }}$.

22. S. Basavarajappa, G. Chandramohan, J. Paulo Davim, "Application of Taguchi techniques to study dry sliding wear behaviour of metal matrix composites", Materials \& Design, vol. 28, pp. 1393-98, 2007.

23. Poovazhagan.La, Kalaichelvan.Ka, Rajadurai Aaand Senthilvelan. "Characterization of Hybrid Silicon Carbide and Boron Carbide Nanoparticles-Reinforced Aluminum Alloy Composites"International Conference On Design And Manufacturing, IConDM 2013,Procedia Engineering 64 ( 2013 ) 681 - 689. 